\section{Coronavirus motif}

SIR - I report the presence of a leucine zipper motif at the carboxyl end of the spike (S) glycoprotein, a transmembrane protein of coronaviruses. All the coronavirus $\mathrm{S}$ proteins whose sequences are known - transmissible gastroenteritis virus (TGEV) FS772/70 (residues 1,3421,377), feline infectious peritonitis virus (FIPV) 79-1146 (1345-1380), mouse hepatitis virus (MHV) A59 (1217-1252), MHV JHM (1128-1163), human coronavirus (HCV) 229E (1,067-1,102), bovine coronavirus (BCV) Mebus $(1,266-1,294)$ and infectious bronchitis virus (IBV) Beaudette $(1,058-1,079)$ - contain a leucine-zipper motif terminating 10 amino-acid residues upstream of the conserved KWP motif preceding the transmembrane domain.

The length of the leucine zippers range from three heptad repeats, as identified for the F glycoprotein of paramyxoviruses, to five heptad repeats. The observation that all coronavirus $\mathrm{S}$ proteins sequenced so far contain the leucine-zipper motif 10 amino-acid residues from the transmembrane domain may imply some function of the motif in the dimerization of the $S$ polypetides.

Institute for Animal Health,

PAUL BRITTON

\section{Compton Laboratory,}

Compton, Newbury RG16 ONN, UK

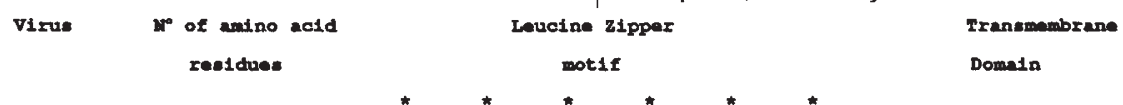

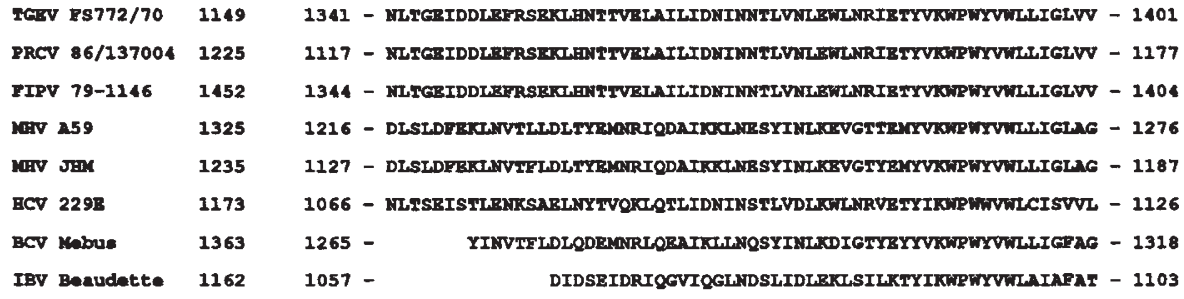

Comparison of the leucine-zipper motifs found in the different coronavirus $S$ proteins. The KWP motif preceding the potential transmembrane domain and the transmembrane domains are also shown. The repeated leucine or isoleucine residues are marked with an asterisk. PRCV, porcine respiratory coronavirus.

\section{Biocontrol risks}

SIR - Hochberg and Waage suggested in their News and Views article ${ }^{1}$ that some new genetically modified insect viruses will be acceptable as biological control agents because they have "highly restricted host ranges". There is widespread agreement that specific biological control agents are much to be preferred, on environmental grounds, over chemical pesticides. But the dangers of nonspecific biocontrols are great, and much damage has resulted from their use ${ }^{2}$.

How specific are these genetically modified organisms? They are derived from the Autographa californica nuclear polyhedrosis virus (AcNPV), a baculovirus, which has a wide and sporadic host range in the lepidoptera. There are around 2,500 species of lepidoptera in Britain $^{3}$, and of course many times more elsewhere. The records of host range of this virus ${ }^{4-6}$, based on a small fraction of the known species, show that, of twelve superfamilies tested. eight apparently contain 'permissive' species (species killed by fewer virus polyhedra than are produced by one dead caterpillar). With this and other baculoviruses one species in a genus may be permissive, others resistant and the LD50s vary markedly between different permissive species, without apparent regard for taxonomy.
The superfamilies known to have permissive species are the Gelichiodea, Pyraloidea, Papilionoidea, Sphingoidea and Noctuoidea: the Bombycoidea, Geometroidea and Yponometroidea may have them, but this needs confirmation by DNA analysis. It seems that 5 10 per cent of British lepidoptera are permissive for AcNPV, a non-native virus, putting 125-250 species at risk, including some of great conservation value.

The two new genetically modified organisms $^{8,9}$, like others derived from the same virus ${ }^{10}$, may have host ranges slightly different from that of the wild type. But unless they can be further engineered to be absolutely specific for a known set of (pest) species, it is difficult to see that they could be used safely in an uncontrolled way in the field. Would not the risk assessment required under EC Directive 90/220, for instance, indicate that they are undesirable?

Hochberg and Waage ${ }^{1}$ also note that "disabling engineered viruses so that they do not persist has some appeal". Removing the polyhedrin gene to produce a non-occluded virus ${ }^{5,10}$ reduces both persistence and, to a small extent, the host range; neither of the two new genetically modified organisms has apparently been modified in this way.

Research into the molecular and other bases of host specificity is likely to be a sine qua non for the successful, muchdesired, replacement of chemical control agents for insects by viral ones.

MARK WILLIAMSON

Department of Biology,

University of York,

York Y01 5DD, UK

1. Hochberg, M. E. \& Waage J. K. Nature 352, 16-17 (1991)

2. Howarth, F. G. A. rev. Ent. 36, $485-509$ (1991).

3. Bradley, J. D. \& Fletcher, D. S. An indexed List of British Butterflies and Moths (Kedleston, Orpington, 1986).

4. Payne, C. C. Fortschr. Zool. 32, 183 - 200 (1986).

5. Bishop, D. H. L., Entwistle, P. F., Cameron, I. R., Allen, C. J. \& Possee, R. D. in The Release of Genetically engineered Micro-organisms (eds Sussman, M., Collins, C. H., Skinner, F. A. \& Stewart-Tull, D. E.) 143-179 (Academic, London, 1988).

6. Réchaussat, L. \& Williamson, M. H. Final Report on a Feasibility Study on the Establishment of European Biotechnology Environmental Release Database (BAP, CEC DGXII, Brussels, 1989)

7. Allaway, G. P. \& Payne, C. C. Ann. appl. Biol. 105 29-37 (1984)

8. Tomalski, M. D. \& Miller, L. K. Nature 352, 82-85 (1991)

9. Stewart, L. M. D. et at. Nature 352, $85-88$ (1991).

10. Bishop, D. H. L. \& Possee, R. D. C. R. Acad. Agric. Fr 75, 157-168 (1989).

\section{Ionicity in silica}

SIR - Kramer et al. ${ }^{1}$ suggest that a change in ionicity is responsible for the transition from the $\alpha$ to the $\beta$ phase in silica. Their $a b$ initio force-field method indicates that an increase by about 0.1 atomic units of the net charge on silicon stabilizes the $\beta$ structure of quartz and cristobalite with respect to the $\alpha$ structures, implying that the former correspond to global minima of the BornOppenheimer potential-energy surface. Our recent Hartree-Fock calculations ${ }^{2}$ on the quartz structures of $\mathrm{SiO}_{2}$ and $\mathrm{GeO}_{2}$ come to opposite conclusions with respect to both the magnitude and the direction of the ionicity effect.

Our calculations were performed at a level of accuracy similar to that of the cluster calculations used to derive the force field of ref. 1 . We used the $P 3_{2} 2_{1}$ space group for both the $\alpha$ and the $\beta$ structures. In $\alpha$ quartz there are two equivalent twinned configurations, $\alpha_{1}$ and $\alpha_{2}$, related by a rotation of the $\mathrm{SiO}_{4}$ tetrahedra around their $\mathrm{C}_{2}$ axes. The corresponding internal coordinate, the tilt angle $\delta$ (ref. 3), is negative in the $\alpha_{1}$ phase, positive in $\alpha_{2}$ and zero in $\beta$.

The net charges calculated by this method should provide reliable trends of ionicity in connected structures when identical basis sets are used. We find that the net charge on silicon decreases

\footnotetext{
1. Kramer, G. J., van Beest, B. W. H. \& van Santen, R. A. Nature 351 636-638 (1991).

. Silvi, B., D'Arco, Ph. \& Causà, M. J. chem. Phys. 93. $7225-7229$ (1990)

3. Grimm, H. \& Dorner, B. J. Phys. Chem. Solids 36 407-413 (1975)

4. Tsuneyuki, S., Aoki, H., Tsukada, M. \& Matsui, Y. Phys. Rev. Lett. 64, 776-779 (1990)

5. Tezuka, Y., Shin, S. \& Ishigame, M. Phys. Rev. Lett. 66 2356--2359 (1991).
} 